\title{
Validation of Hygrothermal Simulations with Wall Performance Experiments in an Environmental Chamber
}

\author{
Mikael Salonvaara ${ }^{1, *}$, Philip Boudreaux ${ }^{1}$, Andre Desjarlais ${ }^{1}$, Florian Antretter $^{2}$, Eric Werling $^{3}$ \\ ${ }^{1}$ Oak Ridge National Laboratory, Building Envelopes and Urban Systems, Oak Ridge, TN, USA \\ ${ }^{2}$ Fraunhofer Institute for Building Physics, Holzkirchen, Germany \\ ${ }^{3}$ Department of Energy, Washington DC, USA
}

\begin{abstract}
Oak Ridge National Laboratory is developing a web tool, built on a rule-based expert system, that aids stakeholders in designing energy-efficient moisture-durable walls. Currently, the tool's expert system database is mostly populated with expert opinion, but work is being done to incorporate durability assessment based on stochastic hygrothermal modeling. Chamber experiments have been conducted to validate the hygrothermal models. The measured temperature and humidity have been compared with those predicted by the hygrothermal model. Experiments and comparison to one-dimensional hygrothermal modeling results were completed with two walls, a Structural Insulated Panel (SIP) based wall and a Concrete Masonry Unit (CMU) based wall. The two walls were succumbed to typical Chicago weather in ORNL's Heat, Air and Moisture chamber. The walls were sequentially exposed to different scenarios, including diffusion, wetting, air leakage and solar radiation. For the most part, the hygrothermal simulations can be successfully used to predict the performance of these wall systems for the moisture transport phenomenon. Errors between measured and simulated values decreased as measurements got closer to the interior side of the wall. The root mean square error was larger for relative humidity (up to $17.5 \%$ - $\mathrm{RH}$ for $\mathrm{CMU}$ ) than for temperature (up to $4.5^{\circ} \mathrm{C}$ for $\mathrm{CMU}$ wall). The errors were larger for the CMU wall than the wood frame wall. The phenomenon, including liquid water, caused large discrepancies between measurement and simulation results, and simulated results showed slower drying of materials than measured results. The one-dimensional nature of the simulation model made simulating air leaks difficult but not impossible.
\end{abstract}

\section{Introduction}

Buildings accounted for $41 \%$ of the primary energy consumption (40.2 quads of energy) in the United States in 2010 [1]. Of this energy, 15.1 quads were consumed by the space heating and cooling of commercial and residential buildings [1]. Of this amount, 5.8 quads are attributable to roofs and walls and 4 quads to infiltration. Based on these data, reducing thermal conduction and increasing envelope airtightness are key factors in reducing the energy consumption in buildings. Applicable research has been completed, and updated building energy codes have increased the required air tightness and thermal resistance in new constructions across the United States, thereby decreasing the energy consumption of new residential homes by over $30 \%$ since 2006.
As building envelopes have become more energyefficient, another challenge has arisen. Moisture plays a key role in building performance. Unwanted moisture can cause mildew, mold, wood rot, fastener corrosion, material degradation through freeze-thaw cycles, condensation on cold surfaces within the envelope, and more. Studies have shown that highly insulated walls have a great risk of high moisture, which can cause structural and health problems. According to Building America, high-R wall assemblies (walls $>$ R-30) have many hours throughout the year when condensation can potentially form inside the wall [2].

Oak Ridge National Laboratory is developing a web tool (bsa.ornl.gov), built on a rule-based expert system, that aids stakeholders in designing energy-efficient moisture-durable walls. Currently, the tool's expert system database is mostly populated with expert opinion,

This manuscript has been authored in part by UT-Battelle, LLC, under contract DE-AC05-00OR22725 with the US Department of Energy (DOE). The US government retains and the publisher, by accepting the article for publication, acknowledges that the US government retains a nonexclusive, paidup, irrevocable, worldwide license to publish or reproduce the published form of this manuscript, or allow others to do so, for US government purposes. DOE will provide public access to these results of federally sponsored research in accordance with the DOE Public Access Plan (http://energy.gov/downloads/doe-public-access-plan).

\footnotetext{
* Corresponding author: salonvaaramh@ornl.gov
} 
but work is being done to incorporate durability assessment based on stochastic hygrothermal modeling. To validate the hygrothermal models that are being used, chamber experiments have been conducted to compare measured temperature and humidity with those the hygrothermal model predicts when the boundary conditions are matched in the model to the experiment. This paper presents results from eight experiments, and the results are compared with hygrothermal modeling results.

\section{METHODS}

\subsection{Heat, air and moisture chamber}

The experimental tests were carried out in the Heat, Air, and Moisture Penetration (HAM) chamber at Oak Ridge National Laboratory (ORNL), shown in Figure 1. This moisture penetration test chamber can simulate interior and exterior environments on either side of the wall. The HAM chamber specifications are shown in Table 1.

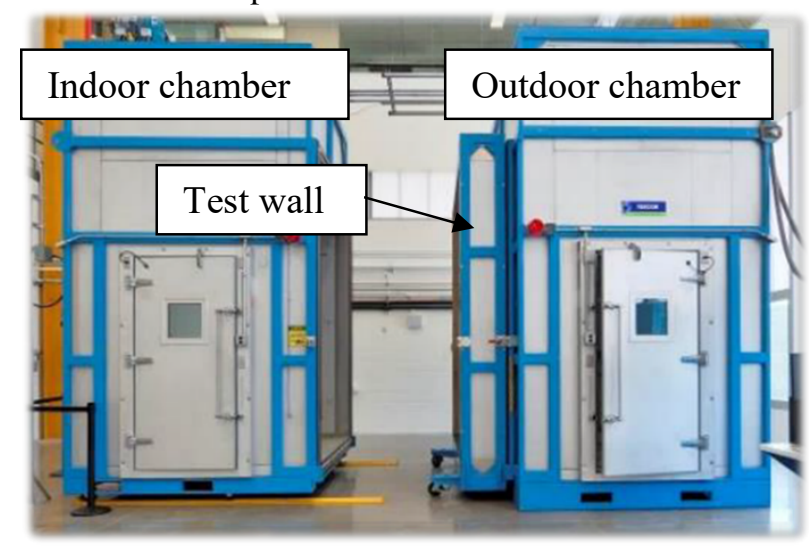

Fig. 1. ORNL Heat, Air, and Moisture Chamber. The indoor chamber slides so that test wall can be rolled in and out.

Table 1. HAM chamber specifications.

\begin{tabular}{|c|c|c|}
\hline & Indoor chamber & Outdoor chamber \\
\hline $\begin{array}{l}\text { Dry bulb } \\
\text { temperature } \\
\left({ }^{\circ} \mathrm{C}\right)^{*}\end{array}$ & $-1-+32$ & $\begin{array}{c}-18-+43(\text { ramp } \\
\text { rate } 0.6- \\
\left.0.8^{\circ} \mathrm{C} / \mathrm{min}\right)\end{array}$ \\
\hline RH [\%]* & $10-90$ & $10-90$ \\
\hline $\begin{array}{l}\text { Dew point } \\
\left({ }^{\circ} \mathrm{C}\right)^{*}\end{array}$ & $-14-+27$ & $-21-+32$ \\
\hline $\begin{array}{l}\text { Pressure } \\
\text { (w.r.t } \\
\text { ambient) } \\
(\mathrm{Pa})^{*} \\
\end{array}$ & $0-75$ (sustained) & $\begin{array}{l} \pm 1200 \text { (pulsed) } \\
\pm 75 \text { (sustained) }\end{array}$ \\
\hline Precipitation & - & $\leq 28 \mathrm{l} / \mathrm{min}$ \\
\hline $\begin{array}{c}\text { Precipitation } \\
\text { temperature } \\
\left({ }^{\circ} \mathrm{C}\right)\end{array}$ & - & $4-35$ \\
\hline $\begin{array}{c}\text { Solar } \\
\text { insolation* }\end{array}$ & - & $\leq 1080 \mathrm{~W} / \mathrm{m}^{2}$ \\
\hline
\end{tabular}

*Steady state and transient-diurnal cycles

Sensors used to measure the hygrothermal state of the test wall materials had the following ranges and accuracy: Temperature sensors (Type $\mathrm{T}$ Thermocouple) have a range $-229-194^{\circ} \mathrm{C}$ and accuracy $\pm 1.0^{\circ} \mathrm{C}$, the relative humidity sensors (Honeywell HIH-4000-003) have a range $0-100 \% \mathrm{RH}$ and accuracy $\pm 3.5 \%$ - $\mathrm{RH}$. The estimated measurement errors, including sensor and data-acquisition uncertainties for the calibrated temperature and relative humidity sensors, are $\pm 1.14^{\circ} \mathrm{C}$ and $\pm 3.5 \%-\mathrm{RH}$, respectively.

\subsection{Hygrothermal model}

WUFI Pro-the model used in this project-is a transient, one-dimensional heat and moisture transfer model that can assess the hygrothermal behavior of a construction. WUFI is a commonly used building industry hygrothermal model and is one of the most advanced hygrothermal models for coupled mass and heat transport analysis [3]. WUFI is based on a state-ofthe-art understanding of physics regarding sorption and suction isotherms, vapor diffusion, liquid transport, and phase changes. The model is also well documented and has been validated by many comparisons between calculated and field performance data $[4,5,6,7]$.

\subsection{Experimental plan}

Two walls were tested in the HAM chamber: one based on concrete masonry units (CMUs) and the other based on structural insulated panels (SIPs). Figure 2 shows each wall assembly in detail. For the CMU-based wall, the layers-starting from the outside and moving to the interior-were 8 in. CMUs, a permeable water resistive barrier (WRB)/air barrier, 38mm of extruded polystyrene (XPS) insulation, a $19 \mathrm{~mm}$ lathe strip to create an air gap between the insulation, and a $12.5 \mathrm{~mm}$ gypsum board. The SIP-based wall had layers of vinyl siding, a 19mm lathe strip to create air gap behind siding, Spunbonded Polyolefin WRB, a $108 \mathrm{~mm}$ SIP panel, and a $12.5 \mathrm{~mm}$ gypsum board. The SIP panel had $11 \mathrm{~mm}$ Oriented Strand Boards (OSB) on either side with R-2.8 of expanded polystyrene (EPS) insulation between the OSBs.

Figure 2 shows the location of temperature and $\mathrm{RH}$ sensors in each wall at two vertical locations that are $\pm 40 \mathrm{~cm}$ from the middle line, which is approximately $1.2 \mathrm{~m}$ from the wall baseplate. Moisture content was measured at similar positions in the western cedar lathe strip in each wall. Finally, the moisture content was also measured in an embedded piece for wood (fir) on the interior side of the CMU block and on the exterior face of the SIP panel. 


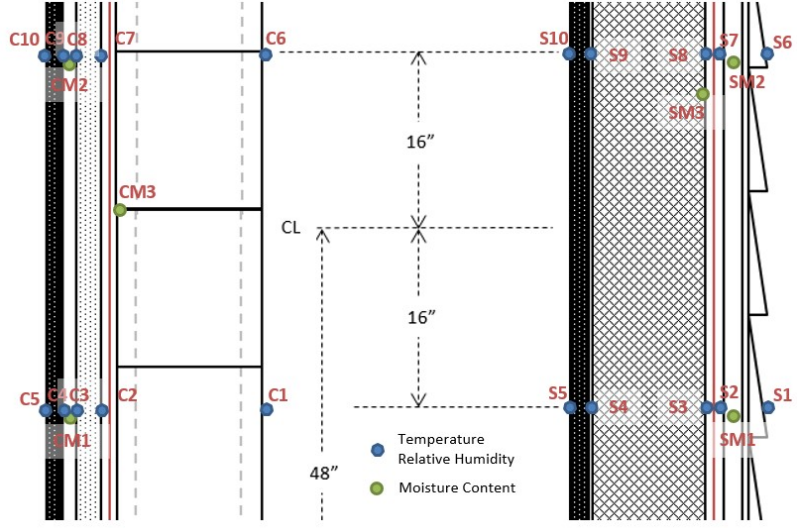

Fig. 2. Location of sensors in each wall with sensor labels where "C" is for CMU wall and "S" is for SIP wall. "SM" and "CM" represent the moisture pins in the SIP and CMU wall, respectively.

For the tests, both winter and summer conditions were simulated in the outdoor room of the chamber. For the interior boundary condition, the indoor chamber was set to a constant $24^{\circ} \mathrm{C} / 50 \% \mathrm{RH}$ for summer and a constant $20^{\circ} \mathrm{C} / 40 \% \mathrm{RH}$ for winter. For the exterior conditions, diurnal temperature and $\mathrm{RH}$ data from the Chicago, Illinois cold-year weather conditions from the WUFI database were used. When the summer conditions were simulated in the chamber, the weather conditions starting on June 1st were used, and when the winter conditions were simulated, weather conditions starting on December 15 th were used. These simulated weather conditions are illustrated in Figure 3; the red box indicates the summer and the blue the winter.

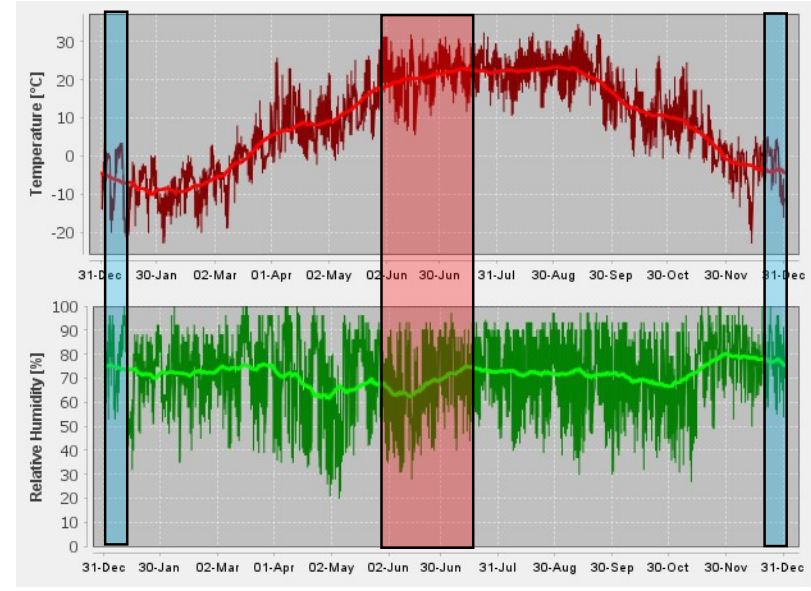

Fig. 3. Exterior boundary conditions for the test wall were taken from the cold-year Chicago weather conditions file from WUFI. The red box indicates the weather conditions that were simulated in the chamber for the summer and the blue for the winter.

The following tests were completed, and the measured results were compared against WUFI simulation output. These tests build on each other, with each round of tests adding one new method of moisture transport.

1. Test walls in the diffusion scenario as the only moisture transport mechanism and compare measured transient temperature and $\mathrm{RH}$ of select wall components under Chicago summer and winter weather conditions with WUFI model results.

2. Test walls in wetting event scenario and compare measured transient temperature and $\mathrm{RH}$ of select wall components under Chicago summer weather conditions with WUFI model results.

To simulate a leak in the cladding, water-saturated $3 \mathrm{~mm}$ polypropylene sorbent sheets were placed inside the wall. To accomplish this, the walls had to be partially dismantled and then reassembled. For the SIP wall, the polypropylene sorbent sheet was added between the SIP panel and housewrap; for the CMU wall it was added between the XPS and the WRB. In both cases, the sheet was added to the interior side of the main moisture barrier, so it simulates damage to the weather resistive barrier in the wall, which would let bulk water into the wall.

3. Test walls in the diffusion/advection scenario. In addition to controlling the outdoor chamber to match real outdoor weather conditions, the pressure differential across the wall was varied. Measured transient temperature and $\mathrm{RH}$ of select wall components were compared with WUFI model results.

4. Test walls in diffusion/advection with solar heating of cladding. In addition to the variables above, heat lamps were used to heat the cladding on a diurnal cycle. Measured transient OSB moisture content and temperature were compared with WUFI model results.

The air infiltration of each wall was determined using the ASTM E283 Standard Test Method [8] before starting the test series. Both walls were very tight with an air leakage rate of $0.002 \mathrm{~L} / \mathrm{s} \mathrm{m}^{2}$ for the SIP wall and $0.051 \mathrm{~L} / \mathrm{s} \mathrm{m}^{2}$ for the CMU wall at $75 \mathrm{~Pa}$.

Note that some walls, such as the CMU wall, as built in the chamber, are not suitable for all climates. The intention was not to study only well-performing walls but also to evaluate modeling results when walls are not expected to perform well.

\subsubsection{Material layers in the modeled test walls}

The modeled layers in the CMU wall from outside to inside are

1. CMU exterior wall

2. Concrete fill

3. CMU interior wall

4. Fluid-applied vapor-permeable air/moisture barrier

5. XPS, 38mm

6. Furred air cavity, $19 \mathrm{~mm}$

7. Interior gypsum board, $12.5 \mathrm{~mm}$

Figure 4 shows the layers and the structure of the CMU wall as modelled in WUFI. 


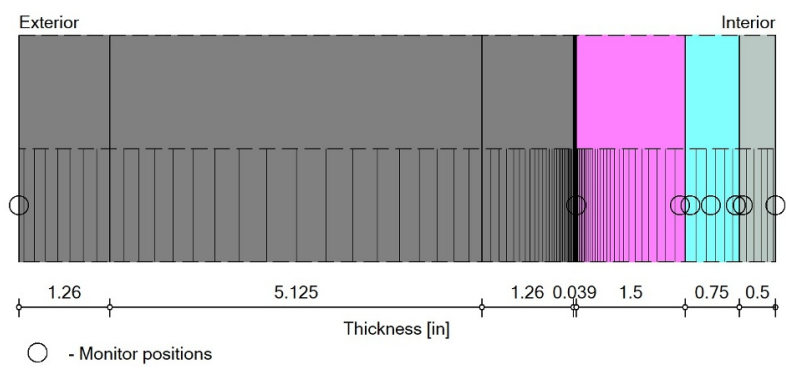

Fig. 4. CMU wall assembly as modeled in WUFI.

The modeled layers in the SIP wall from outside to inside are:

1) Vinyl siding

2) Furred air cavity $19 \mathrm{~mm}$

3) Water resistive barrier (Spunbonded Polyolefin)

4) Air gap $1 \mathrm{~mm}$ (mechanically fastened membrane, space for a sensor reading)

5) SIP panel

a. Oriented Strand Board $11 \mathrm{~mm}$

b. Expanded polystyrene 3.6"

c. Oriented Strand Board $91 \mathrm{~mm}$

6) Interior gypsum board $12.5 \mathrm{~mm}$

For the simulation, the air cavity behind the vinyl siding is vented at an air exchange rate of 40 Air Change per Hour (ACH). Figure 5 shows the layers and the structure of the SIP wall, as modeled in WUFI.

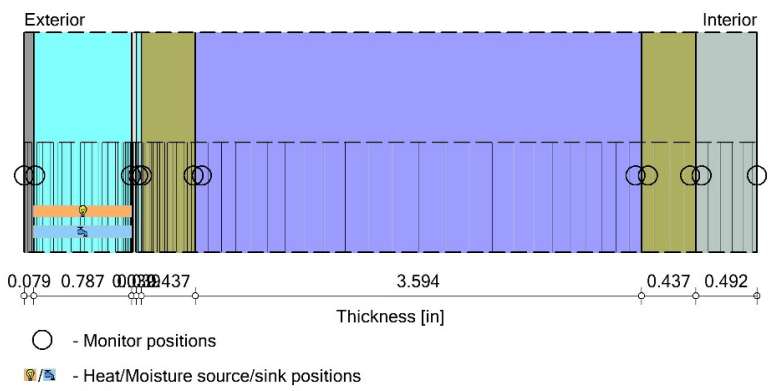

Fig. 5. SIP wall assembly as modeled in WUFI.

The materials for the simulations were taken from the WUFI databases.

\section{RESULTS}

The primary purpose of this work was to demonstrate confidence in the authors' WUFI simulations by comparing simulation results with measured hygrothermal wall performance in an environmental chamber. Experiments were completed with the moisture transport phenomenon of diffusion, bulk moisture intrusion, advection, and solar-driven moisture.
Figure 6 and Figure 7 show simulated temperature (T) and relative humidity $(\mathrm{RH})$ on the exterior side surface of SIP panel between OSB and the WRB, for summer and winter conditions, respectively. The measured data are sensors 3 (lower) and 8 (upper).

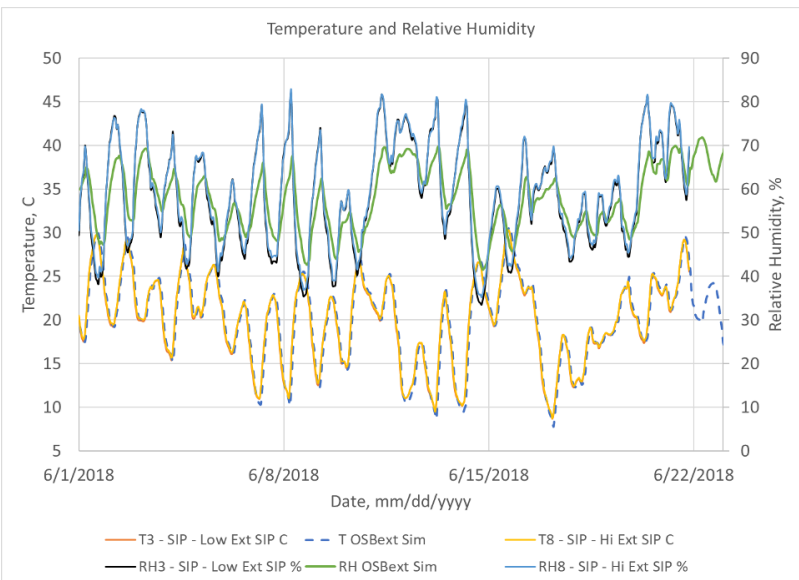

Fig. 6. Diffusion test: SIP wall in summer conditions. The sensor location is between WRB and OSB.

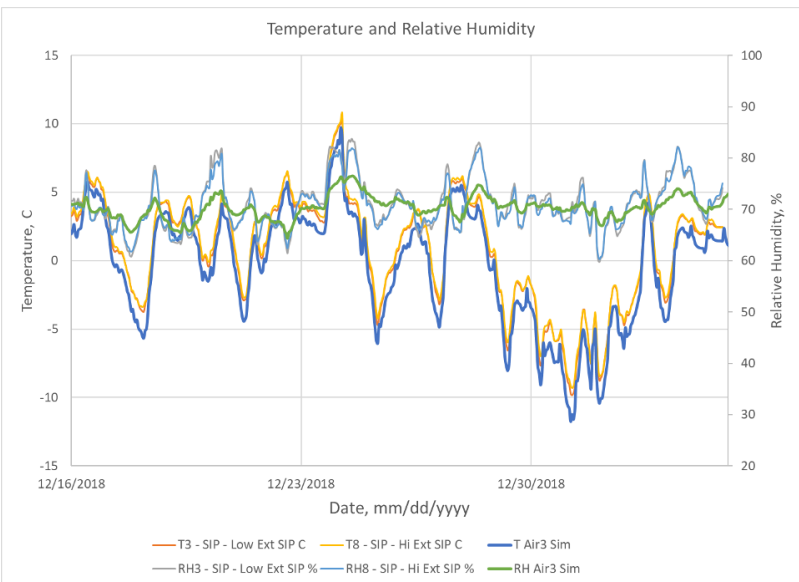

Fig. 7. Diffusion test: SIP wall in winter conditions. The sensor location between WRB and OSB.

The simulated temperatures agree well with the experimental data, but the relative humidity fluctuates in a broader range in measurements than in simulations. The Root Mean Square Errors (RMSE) are for the summer test $0.93^{\circ} \mathrm{C}$ and $6.55 \%$-RH and for the winter test $1.36^{\circ} \mathrm{C}$ and $3.66 \%-\mathrm{RH}$ for temperature and relative humidity, respectively.

\subsubsection{CMU wall}

Figure 8 and Figure 9 show the simulated temperature (T) and relative humidity $(\mathrm{RH})$ on the exterior side surface of XPS insulation in the CMU wall for summer and winter conditions, respectively. Measured data are sensors 2 (lower) and 7 (upper).

\subsection{Diffusion tests}

\subsubsection{SIP wall}




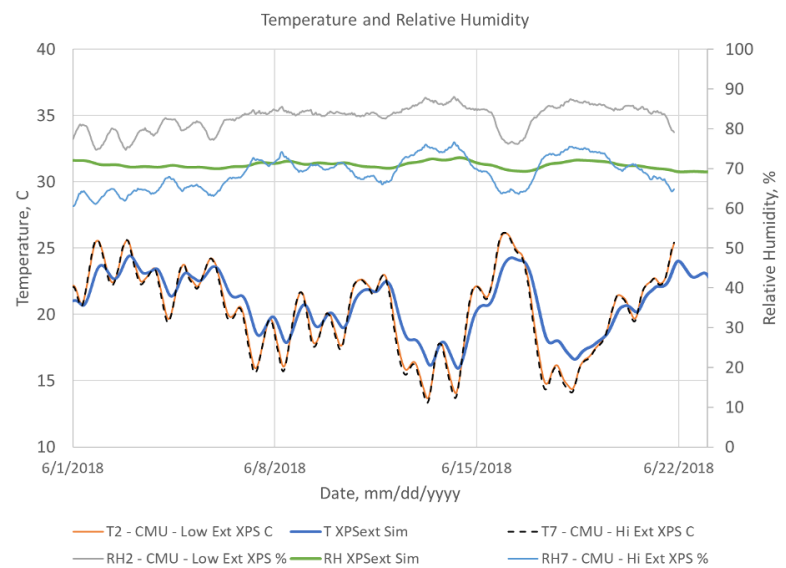

Fig. 8. Diffusion test: CMU wall in summer conditions. The sensor location between the air barrier and XPS.

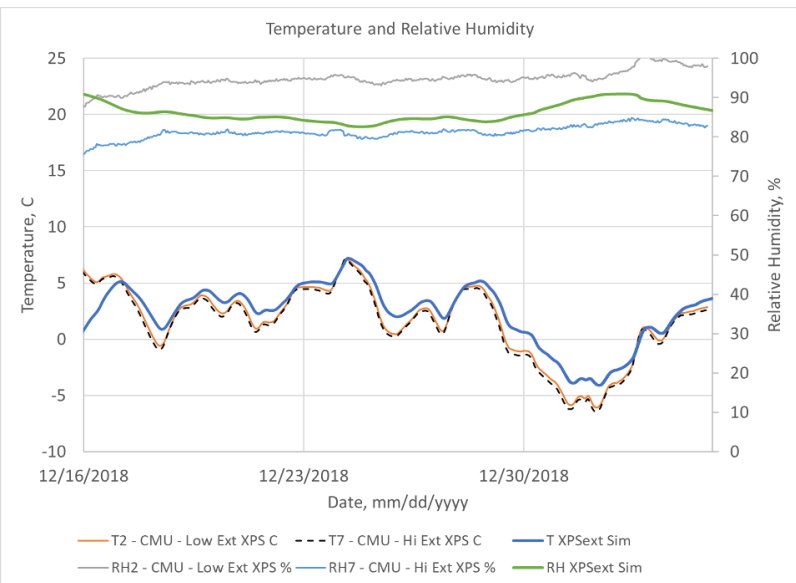

Fig. 9. Diffusion test: CMU wall in winter conditions. The sensor location between the air barrier and XPS.

Considering that generic material properties were used for the CMU block, the simulated temperature agrees well with the measured ones. The simulated temperature and relative humidity show less hourly variation than in the measurements. The Root Mean Square Errors (RMSE) are for the summer test $0.60^{\circ} \mathrm{C}$ and $4.86 \%-\mathrm{RH}$ and for the winter test $0.93^{\circ} \mathrm{C}$ and $6.55 \%-\mathrm{RH}$ for temperature and relative humidity, respectively.

\subsection{Diffusion and wetting tests}

\subsubsection{SIP wall with wetting events}

The wetting event was created in the hygrothermal modeling with WUFI by setting the initial moisture content of the sorbent sheet to the tested moisture content. The amount of water added to the sorbent sheet was divided by the area and the thickness of the layer in the simulation model to insert the volumetric moisture content in the sorbent material.

Figure 10 shows the simulated temperature (T_SIP) and relative humidity (RH_SIP) on the exterior side surface of SIP panel between OSB and the water resistive barrier. Measured data, sensors 3 (lower), and 8 (upper), are between OSB and the water resistive barrier. Data is for summer condition only.

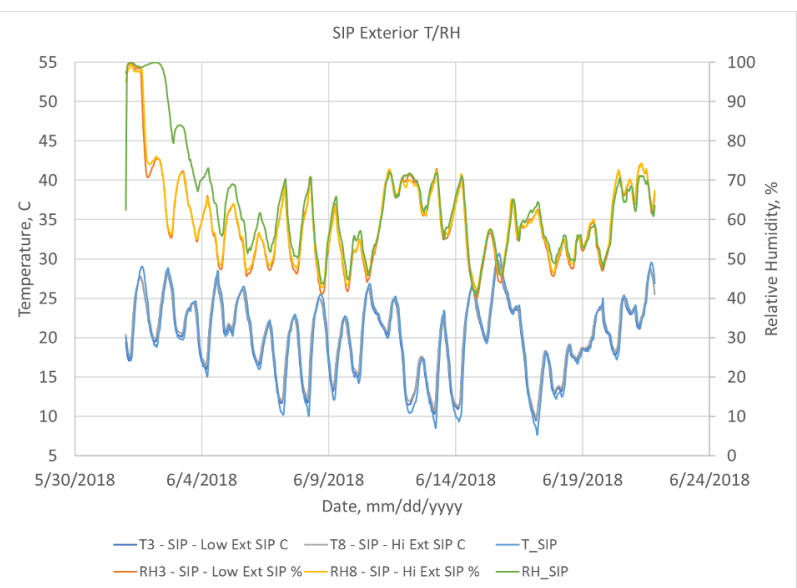

Fig. 10. Wetting test: SIP wall in summer conditions. Sensor location between WRB and OSB.

The simulated drying rate is slower than the measured rate. The Root Mean Square Errors (RMSE) are $1.18^{\circ} \mathrm{C}$ and $7.66 \%-\mathrm{RH}$ for temperature and relative humidity, respectively.

\subsubsection{CMU wall with wetting events}

The test runs for CMU wetting on the WRB included two levels of added water: Full wetting amount (RH_CMU) and a case with half the injected water (RH_CMU, half water). Figure 11 shows the temperature and humidity between the air barrier and XPS insulation.

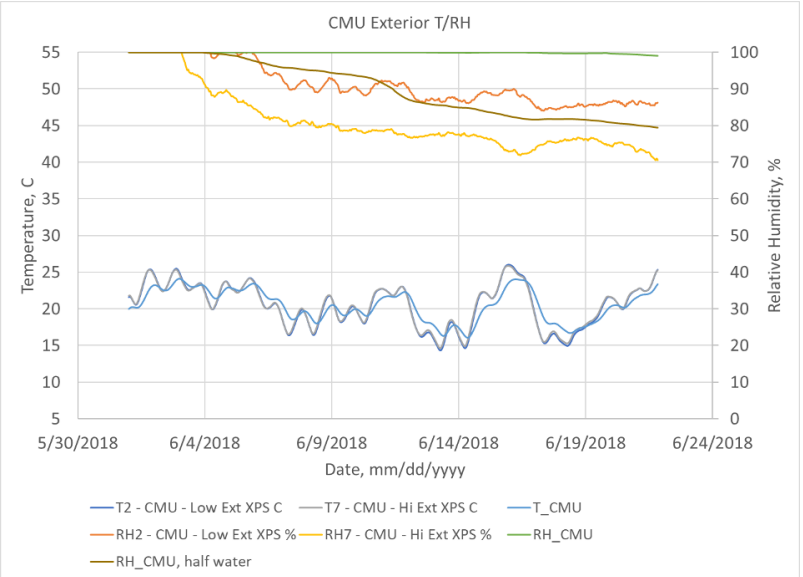

Fig. 11. Wetting test: CMU wall in summer conditions. Sensor location between air barrier and XPS.

The simulated results do not agree with the measured drying rate if the full amount of sprayed water is used. Half of the water shows the correct drying rate, but the relative humidity does not respond to temperature fluctuation as much in simulations as in the measurements. The Root Mean Square Errors (RMSE) for the test with half water are $1.19^{\circ} \mathrm{C}$ and $6.29 \%-\mathrm{RH}$ for temperature and relative humidity, respectively.

\subsection{Diffusion and advection tests}


To capture the effects of air traveling through the wall, holes were made in each wall to give a pathway for air movement. For the SIP wall a hole was made along a horizontal seam where the two SIP panels met. The Spunbonded Polyolefing housewrap and drywall were both cut away to allow unrestricted airflow through the crack shown in Figure 12.

For the leak in the CMU wall, 3 holes with $1 / 2$ inch diameter were drilled through the mortar between two CMU blocks about halfway up the wall. These holes went through the WRB and XPS layers into the cavity created by the lathe strips. Then a small hole was cut through the gypsum toward the bottom of the wall so the air could exit as shown in Figure 13.
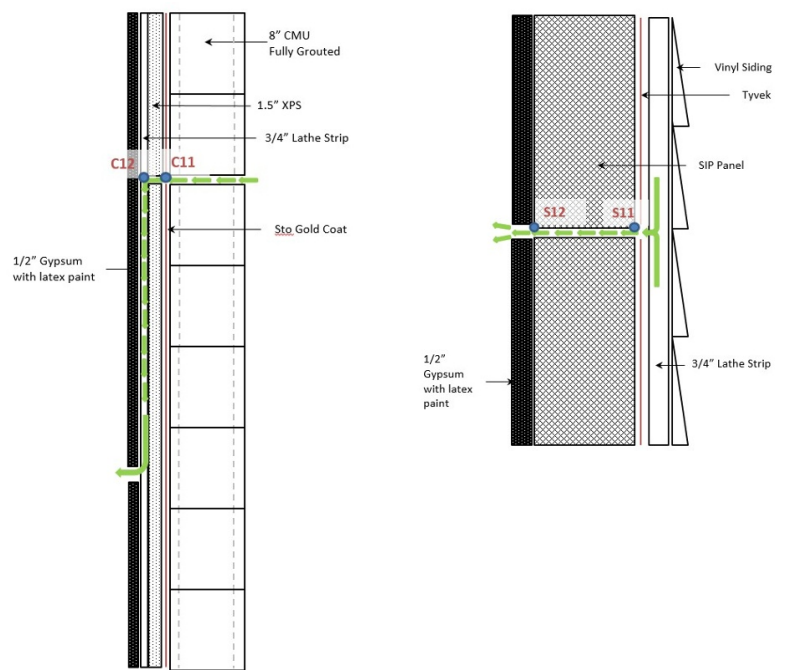

Fig. 12. On the left is a schematic of the CMU wall, and on the right, the SIP with air leak about halfway up the wall. The green arrows represent the airflow path and direction.

To determine the leakage characteristics of the air pathways, the volumetric airflow rate was measured as a function of the pressure differential across the wall according to ASTM E283 Standard Test Method [8] before and after the holes were made.

Chicago summer outdoor weather was followed in the outdoor chamber, and the indoor chamber was set to a constant $24^{\circ} \mathrm{F}$ at $50 \% \mathrm{RH}$. During the test, a target +20 $\mathrm{Pa}$ pressure difference between the outdoor and indoor chamber was maintained so that outdoor air would infiltrate into the wall. At this pressure, the SIP and CMU walls would have a continuous 0.38 and $0.91 / \mathrm{s}$ of air flowing through the leaks, respectively.

\subsubsection{SIP wall}

Figure 13 shows the simulated temperature $(\operatorname{extSIP} \mathrm{T})$ and relative humidity (extSIP RH) on the exterior side surface of the SIP panel during summer conditions with air leakage through the wall. Measured data are sensors 3 (lower) and 8 (upper).

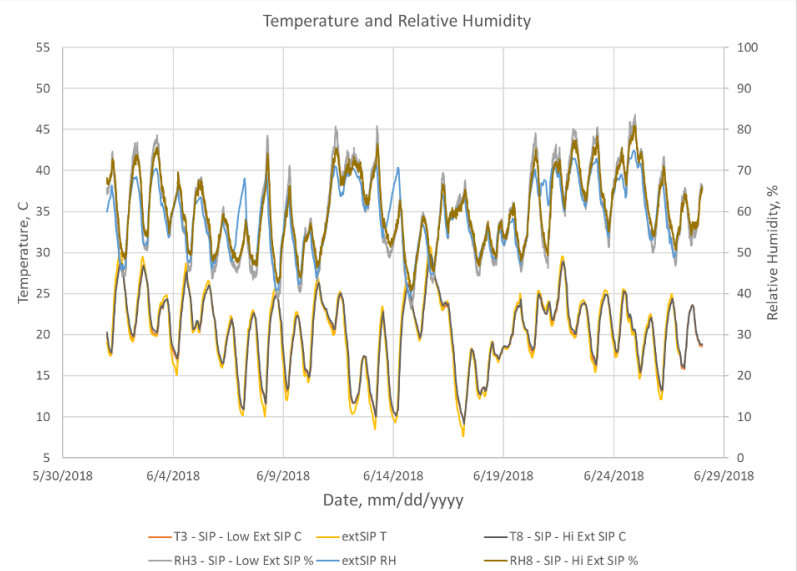

Fig. 13. Air leakage test: SIP wall in summer conditions. Sensor location between WRB and OSB.

The simulated and measured temperature and relative humidity agree well. However, the impact of air leakage on the sensor locations was minimal. The Root Mean Square Errors (RMSE) are $1.30^{\circ} \mathrm{C}$ and $4.53 \%-\mathrm{RH}$ for temperature and relative humidity, respectively.

\subsubsection{CMU wall}

Figure 14 shows the measured temperature (T) and relative humidity $(\mathrm{RH})$ on top and bottom part on the exterior side of the extruded polystyrene (T2, RH7) with simulated temperature (XPSext $\mathrm{T}, \mathrm{F}$ ) and relative humidity (XPSext RH, \%) when air was not leaking to the gap between AB/WRB (air barrier/water resistive barrier) and XPS, and with simulated temperature (XPSext $300 \mathrm{~T}, \mathrm{~F}$ ) and relative humidity (XPSext 300 $\mathrm{RH}, \%$ ) when air was leaking to the gap between $\mathrm{AB} / \mathrm{WRB}$ and XPS.

The simulations agreed well with the measurements when the known air leakage rate was inserted evenly to a thin air gap between the air barrier and the XPS layers indicating that air was indeed capable of spreading in between the layers. The Root Mean Square Errors (RMSE) for the test when air leak was inserted to the gap between $\mathrm{AB} / \mathrm{WRB}$ and $\mathrm{WRB}$ are $4.46^{\circ} \mathrm{C}$ and $17.49 \%$ - RH for temperature and relative humidity, respectively.

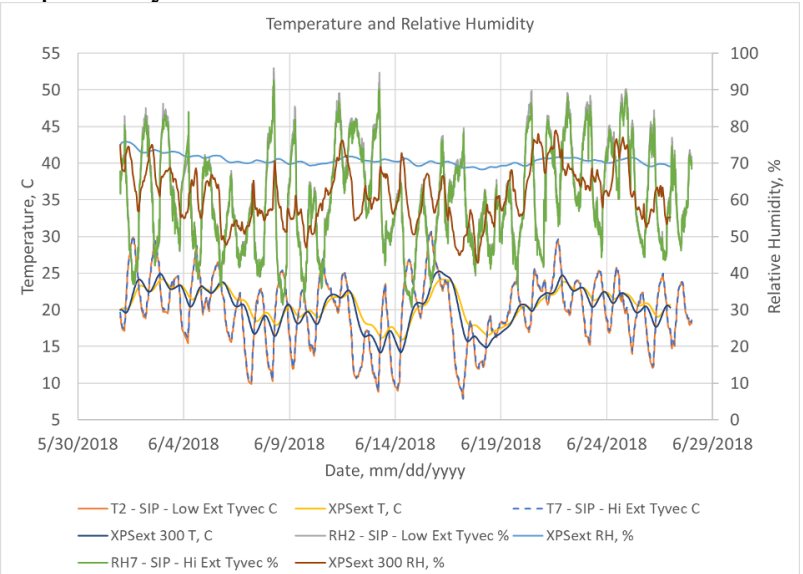

Fig. 14. Air leakage test: CMU wall in summer conditions. Sensor location between the air barrier and XPS. 


\subsection{Diffusion, advection and solar driven tests}

For the final test, solar-driven moisture was added to the modes of moisture transfer that were tested in the chamber. For this test, the CMU wall was focused on. The weather and differential pressure that were simulated were the same as the previous diffusion and advection test. To determine how much solar insolation needed to be incident on the wall, an Energy Plus simulation was run to find the surface temperature of the south-facing façade of a residential home in Chicago for the summer months. These data were used as the target values for the control of the light rack intensity, which uses thermocouples on the wall surface in a closed-loop control system to maintain the target surface temperature of the CMU wall.

To facilitate solar driven moisture, a large section of the CMU was wetted with water using a spray bottle for four consecutive mornings. The amount of retained water was recorded.

The weather conditions for hygrothermal simulations were created by first running WUFI for the wall design with the TMY3 weather file (that was used in Energy Plus simulations) for Chicago by facing the wall towards the south. The resulting solar radiation intensity on the wall in WUFI was outputted to create the hourly solar radiation boundary condition for the subsequent calculations. WUFI weather file type "kli" was created by taking this hourly solar radiation as "measured" solar radiation on the wall. The temperature and relative humidity in both the exterior and the interior chamber were used for ambient conditions. Finally, the wetting events in units mass per wetted wall surface area were used as "measured rain" on the wall in the first four days.

\subsubsection{CMU wall - lower and upper part}

Figure 15 shows the measured temperature (T) and relative humidity $(\mathrm{RH})$ on the lower part of the exterior surface on CMU block (T1, RH1) between the air barrier and extruded polystyrene (XPS) (T2, RH2). "XPSextT" and "XPSext RH" are temperature and relative humidity between the air barrier and XPS, and "Ext T" and "Ext RH" are the simulated temperature and relative humidity on the exterior surface, respectively, are the simulated temperature and relative humidity in the same location. Figure 16 shows the same data for the upper part of the wall.

WUFI simulations are one-dimensional, and the height of the wall does not play a role in the results. In the measured data, however, the top part has higher temperatures than the bottom part on the exterior surface likely due to heat rising from the warm surface that is heated by the radiation, which may only occur during sunny days without wind in actual field conditions. The measured and simulated temperatures have a larger difference in the higher part of the wall (Figure 16) than in the lower part of the wall (Figure 15). The measured relative humidity between the air barrier and the XPS is higher than the measured one in the lower part of the wall. In contrast, the measured relative humidity in the top part of the wall is lower than the simulated value. The largest Root Mean Square Errors (RMSE) for the test were $1.47^{\circ} \mathrm{C}$ and $3.38 \%-\mathrm{RH}$ for temperature and relative humidity, respectively.

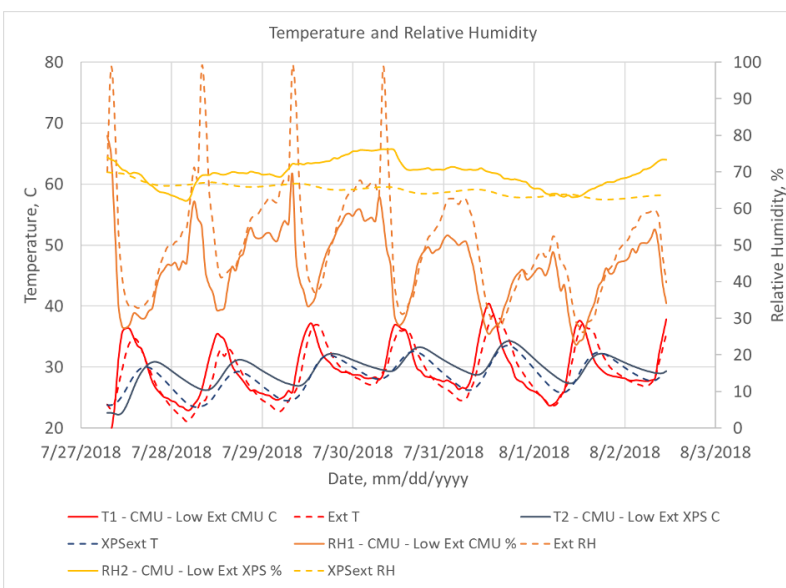

Fig. 15. Solar drive test: CMU wall in summer conditions. Sensor location between air barrier and XPS in the lower part.

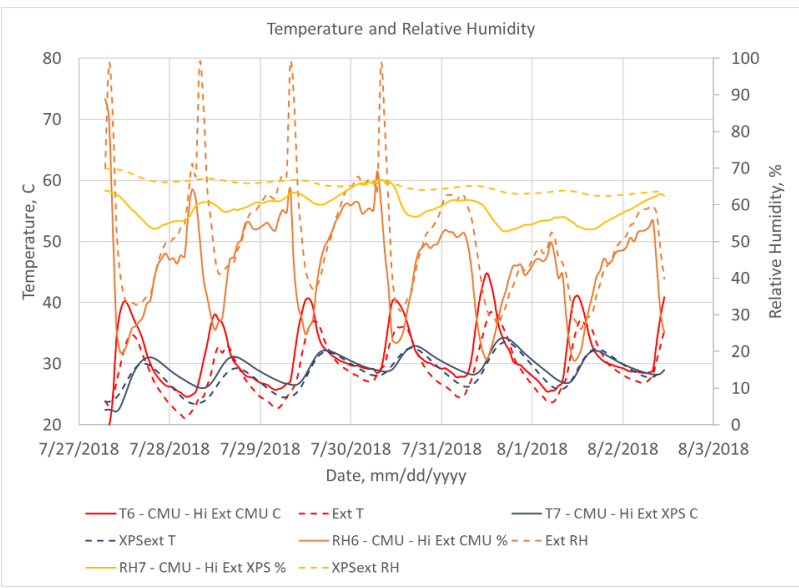

Fig. 16. Solar drive test: CMU wall in summer conditions. Sensor location between the air barrier and XPS in the upper part.

\subsection{Differences between simulated and measured results}

Table 2 and Table 3 show the root mean square error in each experiment between measured and simulated results for key measurement locations of temperature and RH. The average differences were typically much lower than the maximum differences that usually occurred over a short time in the test.

Table 2. Root mean square error (RMSE) between measured and simulated performance of CMU wall at key locations.

\begin{tabular}{|l|l|l|l|l|l|}
\hline $\begin{array}{l}\text { Test for } \\
\text { CMU Wall }\end{array}$ & Season & \multicolumn{2}{|l|}{$\begin{array}{l}\text { Interior } \\
\text { Surface of } \\
\text { XPS }\end{array}$} & \multicolumn{2}{l|}{$\begin{array}{l}\text { Exterior Surface of } \\
\text { XPS }\end{array}$} \\
\hline & & T & RH & T & RH \\
\hline Diffusion & Summer & 0.33 & 0.83 & 0.60 & 4.86 \\
\hline & Winter & 0.23 & 0.49 & 0.93 & 6.55 \\
\hline
\end{tabular}




\begin{tabular}{|l|l|l|l|l|l|}
\hline $\begin{array}{l}\text { Bulk } \\
\text { Moisture }\end{array}$ & Summer & 0.59 & 2.57 & 1.19 & $\begin{array}{l}7.50 / \\
6.29^{*}\end{array}$ \\
\hline $\begin{array}{l}\text { Diffusion + } \\
\text { Advection }\end{array}$ & Summer & 0.85 & 16.77 & 4.46 & 17.49 \\
\hline $\begin{array}{l}\text { Diffusion + } \\
\text { Advection+ } \\
\text { SDM }\end{array}$ & Summer & 0.32 & 6.01 & 1.47 & 3.38 \\
\hline
\end{tabular}

*Half of injected water

Table 3. Root mean square error (RMSE) between measured and simulated performance of SIP wall at key locations.

\begin{tabular}{|l|l|l|l|l|l|}
\hline $\begin{array}{l}\text { Test for } \\
\text { SIP Wall }\end{array}$ & S/W & \multicolumn{2}{|l|}{$\begin{array}{l}\text { Interior Surface of } \\
\text { SIP }\end{array}$} & \multicolumn{2}{l|}{ Exterior Surface of } \\
SIP
\end{tabular}

\section{CONCLUSIONS}

The errors between the measured and the simulated values decreased as measurements got closer to the interior side of the wall. That is expected because the indoor conditions do not vary as much as the conditions on the exterior side of the walls. Liquid water intrusion created by the wetting events in the walls caused significant discrepancies between the measured and simulated results. The simulated results showed slower drying of materials than the measured results, which can be caused by the material properties that were taken from the database of the simulation tool instead of measuring the properties for the specific materials used in the walls. Lastly, the one-dimensional nature of WUFI Pro made simulating air leaks difficult. The air leaks that were intentionally made in these walls did not affect the materials. The flow rates and the flow paths were such that the air leaks would be better characterized as "energy leaks" than "moisture leaks" [9]. In this case, one-dimensional simulation tools can sometimes be used to estimate the impact of the air leakage on the conditions in air cavities between materials when there is no direct and easy way out of the cavity, and the air must travel along the air cavity. Thus, air leaks can be modeled by using an air source in a cavity in the $1 \mathrm{D}$ wall.

For the most part, the hygrothermal simulations can be successful and predict the performance of these wall systems for the moisture transport phenomenon. Exposure of walls to ambient temperature and humidity are well replicated in simulation results. Difficulties to accurately predict moisture performance occur more often when rapid temperature or moisture loads take place on the walls, such as due to solar radiation and wind-driven rain.

A full report on this study is available [10].

The authors would like to thank the U.S. Department of Energy for funding this research. This manuscript has been authored by UT-Battelle, LLC, for the US Department of Energy under contract DE-AC05-00OR22725.

\section{References}

1. DOE. 2014. U.S. Department of Energy - Buildings Technologies Office.

2. "High-R Walls." 2013. Building America Top Innovations Hall of Fame Profile, 2. DOE Building Technologies Program.

3. IBP, Fraunhofer. http://www.wufi.de/index_e.html.

4. Holm, Andreas, and Hartwig Kunzel. 1999. 5th Symposium on Building Physics in the Nordic Countries, 677-84. Göteborg.

5. Kunzel, Hartwig. 1995. IRB Verlag

6. Kunzel, Hartwig, K. Kiebl, and M. Krus. 1995. International symposium on moisture problems in building walls, 258-65. Porto.

7. Kunzel, Hartwig, and K. Kiebl. 1996. Internationale Zeitschrift für Bauinstandsetzen 2, 87-100.

8. ASTM E283 / E283M-19, Standard Test Method for Determining Rate of Air Leakage Through Exterior Windows, Skylights, Curtain Walls, and Doors Under Specified Pressure Differences Across the Specimen, ASTM International, West Conshohocken, PA, 2019, www.astm.org

9. Künzel, H.M., D. Zirkelbach, and B Schafaczek. 2011. 9th Nordic Symposium on Building Physics NSB 2011, Tampere, Finland.

10. Philip Boudreaux, Mikael Salonvaara, Florian Antretter, Andre Desjarlais. December 2019. ORNL/TM-2019/1369. 